\title{
MODELACIÓN DEL SECADO DE RENOVALES DE CANELO BASADO EN EL COEFICIENTE GLOBAL DE SECADO ${ }^{1}$
}

Tesis presentada en conformidad a los requisitos para obtener el grado de Magíster en Ciencia y Tecnología de la Madera, Departamento de Ingeniería en Maderas, Facultad de Ingeniería, Universidad del Bío-Bío, Concepción, Chile.

Patricio Pérez Guerrero ${ }^{2}$

\section{RESUMEN}

Esta tesis fue estructurada en base a tres artículos científicos. En el primer artículo titulado "Estudio experimental del secado de renovales de canelo", se estudiaron programas del secado para la madera de renovales de canelo y se evaluó la calidad de la madera seca y el tiempo de secado, de acuerdo al compromiso entre el nivel de defectos atribuibles al proceso y el tiempo de secado (Pérez et al.2007). En el segundo capítulo que se denominó "Estudio de la velocidad de secado de renovales de canelo Drimys winteri", se estudió la velocidad del secado de la madera de renovales de canelo, considerando ensayos experimentales a temperaturas convencionales (Pérez et al. 2005). En el tercer artículo titulado "Modelación del secado convencional de renovales de canelo basada en el coeficiente global de secado", se modeló la evolución de la temperatura y del contenido de humedad del ambiente y de la madera en toda una carga de secado, en ensayos a escala de laboratorio, que luego se validaron a nivel industrial (Ananías et al. 2008). Los resultados fueron: a) los programas de secado adecuados para tablas de un espesor de $25 \mathrm{~mm}$ y de $50 \mathrm{~mm}$, lográndose condiciones de secado adecuadas y un nivel de secado muy bueno para $25 \mathrm{~mm}$ y satisfactorio para $50 \mathrm{~mm}, \mathrm{~b}$ ) las predicciones de la evolución de la temperatura y humedad del ambiente y de la madera durante el proceso de secado,c) que la modelación no fue afectada por el cambio de escala de laboratorio a nivel industrial.

\section{REFERENCIAS}

Ananías, R.A.; Pérez, P.; Salinas, C. 2008. Drying modeling of canelo regrowth. In CD Proceeding of 51st Society of Wood Science and Technology Annual Convention. Universidad del Bío-Bío, Concepción, Chile.

Pérez, P.; Ananías, R.A.; Hernández, G. 2007. Estudio experimental del secado de renovales de canelo. Maderas. Ciencia y tecnología 9(1):59-70.

Pérez, P.; Ananías, R.A.; Hernández, G. 2005. Estudio de la velocidad del secado de los renovales de canelo. Drimys winteri. Maderas. Ciencia y tecnología 7(2): 99-108.

Disponible en texto completo online como Cybertesis de la Universidad del Bío-Bío. Directores de Tesis Rubén A. ANANIAS y Carlos SALINAS.

2 Actualmente estudiante del Doctorado en Ciencias e Industrias de la Madera. Departamento de Ingeniería en Maderas, Facultad de Ingeniería,

Universidad del Bío-Bío, Concepción, Chile.

Autor para correspondencia: pperezg@alumnos.ubiobio.cl 
